\title{
Analysis of Computational's Software Resources for Simulation and Modeling of Energy Flows in Buildings*
}

\author{
Denilson França Moreira, Osvaldo Luiz Gonçalves Quelhas, José Adilson de Castro \\ University Federal Fluminense, Niteroi-RJ, Brazil \\ Valdir de Jesus Lameira \\ University of Coimbra, Coimbra, Portugal
}

\begin{abstract}
Due to the technological development, energy consumption is growing in an exaggerated manner, both in developed countries, and in the developing world. The awareness that the planet does not have resources to supply the waste of all, created studies to meet this demand taking into account the main factor, the environmental sustainability. This research presents an overview of the concepts of energy efficiency using computational resources to support designers and users in order to optimize the use of electric energy in buildings. In the case studying, the research evaluates the computational resource PLUS MARK IV and presented a proposal for updating through a critical analysis of experts on the use of this computer instrument, by using energetic efficiency analysis projects on the electric facilities at the civil engineering. It confirmed the importance of the computer instruments to perform energetic diagnoses, enabling the observation that energetic diagnoses create more aware energy consumption criteria. The possibility for improvements on the computer instrument MARK IV PLUS, through the analysis and critiques to its application at the civil engineering, was observed. Finally, the consulting activity, performed by professionals working for private companies or even in academia, is also an important channel for spreading computational resources for simulation and diagnosis of energy resources. The rapprochement between research centers and companies should contribute to the development of research and generate new knowledge on energy efficiency in buildings. The university-enterprise integration through education and research, should lead to the production of new knowledge and vocational training quality.
\end{abstract}

Keywords: computational's software, construction, energy efficiency, engineering sustainability

\footnotetext{
* Acknowledgement: To the chief of the ELETROBRAS Energetic Efficiencies Projects Department Fernando P.D. PERRONE, who headed me in the search of information related to public governmental policy and he performed as an evaluator member of my examining board. To the Vice-President (Research \& International Relations), University of Western Ontario, Ph.D. Ted Hewitt, to whom the author is deeply thankful for all the support and the accomplishment of the author's background, and who the author admires as both a human being and for his professional generosity.

Denilson França Moreira, M.Sc., Civil Engineering, Metallurgical Department, University Federal Fluminense.

Osvaldo Luiz Gonçalves Quelhas, D.Sc., Coordinador of the Production Engineering Department, University Federal Fluminense.

José Adilson de Castro, PhD. Currently Coordinator of the Graduate Program in Metallurgical Engineering Department, University Federal Fluminense.

Valdir de Jesus Lameira, Ph.D. in Finance, University of Coimbra.

Correspondence concerning this article should be addressed to Denilson França Moreira, Rua Almirante Justino Proenca 632-Campo Grande, CEP 23090-310. E-mail: dfrancamo@gmail.com.
} 


\section{Introduction}

The discourse of corporate sustainability has broadcast in different parts of the field of research like in academic and business area.

Sustainability and Business Ethics, according to Barbosa (2007), is characterized as an interdisciplinary term. Public policies have been developed in the country and internationally in the construction industry, supporting practices aligned with sustainability (UNEP, 2007). Norman (2003) presents the relevance of research and development into energy to enable economic, social and environmental sector in Brazil. The IPCC (2007) estimated that approximately $30 \%$ of $\mathrm{CO}_{2}$ emissions from buildings can be avoided in 2020 . For this, it suggests more efficient heating, cooling, lighting and appliances. Exploiting this potential in construction industry contributes to global sustainability. According to the IPCC (2007), the main ways to modify the emission of greenhouse gases are: awareness of the need to establish criteria for energy consumption, replacing fossil fuels with renewable energy and increasing energy efficiency. Measures to improve energy efficiency in energy consumption are among the most important options to reduce emissions of greenhouse gases in the construction industry. In this context it is relevant to perform energy diagnostics in buildings. It is identified as equally important, the use of computing resources that provide improvement in the effectiveness of projects and in the use of buildings, balancing the economic and environmental outcomes in buildings as in Lee, J. S. Kim, and J. J. Kim (2003).

\section{The Formulation of Analysis Problems}

This research aims to answer the central question: What are the opportunities for improvement of the "MARK IV" program diagnosis for simulations and modeling of energy flows in buildings?

This research analyzes how the computational tools can influence the energy efficiency of buildings. It should study the concepts of optimization in the use of electricity in the Brazilian market buildings.

\section{Basics Assumptions and Research Objectives}

It has specific objectives: To analyze the computational resource "PLUS MARK IV"; propose guidelines for the improvement of computer resources, other computing resources present for evaluation of building energy performance. To answer the central research question and achieve, the proposed objectives are formulated the basics assumptions: (1) the use of energy diagnosis contributes to improve energy efficiency in construction; (2) the use of energy diagnostic encourages a rational and sustainable consumption of energy; and (3) the use of computational resources enables the application of the concepts of energy efficiency in buildings during the design stages.

\section{Research Methodology}

It is about a descriptive research which has as its object of study the use of computational resources to improve the energy efficiency performance in the Brazilian construction industry. For the data collection, two questionnaires were answered by experts in the use of computational resources and energy efficiency. The questionnaires were aimed at clarifying the research questions, hypotheses and objectives. Issues questionnaire components were intended to collect critical to the performance of computer resources.

The preparation of the questionnaire was based on the use of analytical model of strategic management of 
energy according to Sola (2006). For the questionnaires elaboration, five dimensions for analysis of the "MARK IV PLUS" were created: architectural dimensions, economical, ecological, social and political. Each specific objective has been observed using one or more questions, as presented in Table 1.

Table 1

The Questionnaire Composition and Its Links With the Research Objectives

\begin{tabular}{|l|l|}
\hline Questionnaire & Research goals \\
\hline $\begin{array}{l}\text { Architectural } \\
\text { dimension }\end{array}$ & $\begin{array}{l}\text { Identify the sector where the studying program has being applied and how it presents the surroundings of the } \\
\text { analyzed building, as well as whether the program helps to create energetically efficient projects. }\end{array}$ \\
\hline $\begin{array}{l}\text { Economic } \\
\text { dimension }\end{array}$ & $\begin{array}{l}\text { Demonstrate savings in energy expenses, identify if there was any investment in more efficient equipment and } \\
\text { if there is an awareness of the fact that the energy savings decrease the needs for new investments in power } \\
\text { generation. }\end{array}$ \\
\hline $\begin{array}{l}\text { Ecological } \\
\text { dimension }\end{array}$ & $\begin{array}{l}\text { Note the recommendation of some system of generating energy from renewable sources and if there is } \\
\text { awareness that energy efficiency reduces the environmental impact of sources of energy. }\end{array}$ \\
\hline Social dimension & $\begin{array}{l}\text { Identify whether there was transfer of knowledge to form a critical mass in implementing the program, if there } \\
\text { was the recommendation of administrative measures to manage the energy consumption and identify if the } \\
\text { MARK IV PLUS can be used by people without specific knowledge. }\end{array}$ \\
\hline Political dimension the goal of energy efficiency, knowing \\
\hline
\end{tabular} \begin{tabular}{l}
$\begin{array}{l}\text { Check the company's partnership with some public institutions, with the opinion of experts about the possibility of building a distribution network of intelligent energy and evaluate } \\
\text { the opinion } \\
\text { the participation of PROCEL as the responsible body for implementing public policy. }\end{array}$ \\
\hline
\end{tabular}

The first questionnaires was sent to 20 experts and the second to 29 experts, respectively. The experts use to work in the area of energy efficiency and users of computer resources to diagnose energy. The expert group who answered the first questionnaire (see Appendix A) consists of 20 professionals from public, private and educational institutions. The survey was conducted on Juanary 9, 2010, in the first meeting of 2010, the ABNT/CCE-116 Energy Management—group of the Committee 242-ISO 50001.

In the meeting all members were requested to answer the questionnaire. Respondents were 20 experts. Three were familiar with the computational tool MARK IV. Because of their only knowing of the old version of the program, they said they could not continue to answer the questionnaire over the ignorance of its new version. With an attempt to find experts who could answer the survey the UNIFEI was founded. It is an institution responsible for developing the software for the purpose of nominating experts who could answer the questionnaire. The UNIFEI institution did not provide experts to participate in the study.

\section{Market Challenge: Energy Efficiency in Buildings}

The concept of energy efficiency is linked to the idea of minimizing the losses in converting primary energy into useful energy as Sola and Kovaleski (2006). The regulation of energy efficiency measures and the dissemination of its culture give rise to public policies that lead to the conservation of energy. According to Lee and Yik (2003), public policies in the area of energy efficiency for buildings use various instruments. For instance, the creation of mandatory standards and codes, as well as providing certifications that may be voluntary in nature, such as agreements and seals of efficiency. The list of policy measures used to improve the energy efficiency of buildings includes some regulatory instruments: building codes (energy efficiency standards for buildings), economic instruments such as cooperative acquisition, fiscal measures (taxes and energy subsidies) and voluntary or informational instruments (voluntary labeling of appliances). Mendes (2005) recommends the use of computational tools for simulation of thermal, energy and light behavior 


\section{Energy Management: Applying of Computer Instruments}

\section{Energy Management}

According to Sola (2006), the energy management should include aspects of management (contracts, pricing system, uses of technologies, quality, monitoring, energy audit), of strategy (scenario analysis, systems integration and IT management environmental indicators, projects and economic analysis) and the human aspects (academic education and skill level, pay plan, as well as, career and professional recognition). The strategic management of energy means to manage energy use. The management process needs to be supported by a methodology as in Oliveira (2004).

Haddad (2006) reports that the Federal Government through the PROCEL issued technical guide, "energy management", with the aim of encouraging companies to reduce their energy costs. Some model proposed in this Guide is based on "audit energetic". Under the energy management, Norman (2003) examines the financial crisis, energy and sustainability in Brazil and suggests tips for investment in research which integrates universities, enterprises and government

\section{Energy Diagnosis}

According to Alvez (1998), the energy diagnosis aims at determining the current conditions of the facility, from the point of view of energy use, identifying problems and recommending possible solutions. The completion of the energy diagnostic begins by understanding the energy situation of the installation: the use of conditions of renewable energy consumption on the premises, electrical measurements in sectors with greater consumption.

\section{Computational Tools}

They play a fundamental role in the development of analytical models that represent the energy performance of the buildings, allowing the simulation and analysis of different scenarios. Based on Motta (1985), the use of computational tools allows flexibility to investigate the performance of a system during a specified time. Mendes (2005) presents historical evolution of software tools for energy simulation in buildings. The DOE-2 is a kind of software which simulates the behavior of the building, demanding weather information, the description of the building, the air conditioning system and tariff structure. According to Mathews (1998), DOE-2 is an internationally recognized program, however, its interface is not friendly, what consequently restricts its applications to the consultants and research centers.

ESP-r is a general analysis program capable of performing thermal analysis of the building, air flow between zones, air movement within the zones, air conditioning and electrical systems. It has being developed for over 25 years. This product allows the user to increase the complexity of the simulation with project information, what makes of this tool a valuable resource for the milestone. It is a set of tools that can import CAD files and export files to Radiance. The program provides tutorials to help new users and was developed to be used by designers (Crawley et al., 2005). In the 1990s, research centers and companies invested in the development of interfaces for these programs which were compatible with the Windows operating system since when more modern and complex programs have being developed, such as Energy Plus, the FLUENT, CFX and the PHOENICS.

According to Melo (2009), the Energy Plus is a computational tool, created from the programs BLAST and DOE-2 and distributed by the United States Energy Department, for the prediction of heat load and energy 
analysis of buildings and their systems. This program is endorsed by BEPAC Conduction Test, HVAC BESTEST, Furnace BESTEST and has being evaluated by the HVAC BESTEST (volume 1) as in Crawley (2005). It is capable of different simulating, such as time-step calculation in less than an hour, modular system, the possibility of calculating differed air infiltration for each thermal zone, the calculation of thermal comfort indices and integration with other systems (photovoltaic, solar heating, etc...). The Energy Plus program includes several modules that work together to calculate the energy required to heat or cool a building using a variety of systems and energy sources. It does so by simulating the building and associated systems in different environmental and operating conditions. The Energy Plus program was recognized as one of the top 100 tech products in 2003 at the 41th R\&D 100 Awards. It also received the award for Excellence in Technology Transfer in 2002 and 2004, and yet also, the program was awarded IT Quality for Technical Excellence.

The RETScreen Clean Energy Project Analysis Software is a free software package used to determine the feasibility of clean energy projects, which includes renewable energy installations and the means to assess a wide range of energy efficiency options. RETScreen is managed under the leadership and ongoing financial support of the CanmetENERGY research centre of Natural Resources Canada, a department of the government of Canada. The first version of RETScreen was released on April 30, 1998. The current version (number four) was launched on December 11, 2007. The software provides the user with a broad range of options for assessing the technical, financial and environmental suitability for an investment in a "clean energy" project, which includes energy efficiency, renewable energy, and cogeneration (combined heat and power). It integrates a number of databases to assist the site assessor, including a global database of climatic conditions obtained from 4,700 ground-based stations and NASA's satellite data (RETScreen, 2011). This tool allows computational modeling based on scenario analysis of energy development and environmental effects. These scenarios are based on the detailed presentation of how energy is consumed, converted and produced in a region, creating a scenario of how an energy system might evolve over time in a particular socioeconomic system and a set of constraints on energy policy. The model determines power requirements, costs, benefits and associated environmental impact for each scenario definition. Currently, there are over 290 programs listed in the Building Energy Tools Directory (Maliska, 2001).

Table 2

Computational Resources Available for Development of Energy Efficiency in Buildings

\begin{tabular}{|l|l|l|}
\hline Institution & Software name & Utility \\
\hline $\begin{array}{l}\text { Procel-Ministério } \\
\text { Minas e Energia-Brazil de Plus }\end{array}$ & $\begin{array}{l}\text { Mark It analyzes data from different configurations of electric equipment } \\
\text { http://www.procel.gov.br/pr } \\
\text { ocel/site/dols/index.asp }\end{array}$ & $\begin{array}{l}\text { installation, checking the feasibility of implementing conservation } \\
\text { measures for the efficient use of energy. }\end{array}$ \\
\hline $\begin{array}{l}\text { Natural Resources } \\
\text { Canada-Canada }\end{array}$ & $\begin{array}{l}\text { RETScreen } \\
\text { http://www.retscreen.net/an } \\
\text { g/home.php }\end{array}$ & $\begin{array}{l}\text { Can be used worldwide to monitor, analyse, and report key energy } \\
\text { performance data to facility operators, managers and senior } \\
\text { decision-makers. }\end{array}$ \\
\hline $\begin{array}{l}\text { EERE-Energy Efficiency } \\
\text { and Renewable Energy-US } \\
\text { Department of Energy }\end{array}$ & $\begin{array}{l}\text { Energy Plus } \\
\text { http://www.eere.energy.gov } \\
\text { /builigings/energyplus }\end{array}$ & $\begin{array}{l}\text { Modeling and simulation of energy flows in a building for } \\
\text { environmental conditioning, lighting, ventilation, and other uses. }\end{array}$ \\
\hline $\begin{array}{l}\text { Department } \\
\text { Energy-USA }\end{array}$ & $\begin{array}{l}\text { DOE-2 } \\
\text { http://www.eere.energy.gov } \\
\text { /buildings/tools_directory/d } \\
\text { oe_sponsored.cfm }\end{array}$ & $\begin{array}{l}\text { Analysis of the buildings energy performance of and calculation of } \\
\text { operation cost. }\end{array}$ \\
\hline
\end{tabular}


A Brazilian program appears on the list: the UMIDUS, designed to simulate the flow of heat and moisture in building components. Some research groups in the country stood out, using existing software tools or developing their own codes and algorithms to promote the development of more efficient building designs. By the means of simulation, we may evaluate the thermal and energy performance of buildings for different design alternatives. They might be architectural design options, building components, lighting or air conditioning systems. With computer simulation, we can estimate the energy consumption, its cost and even the environmental impact caused by the alternative project before its implementation. In 1993 Eletrobrás launched the computer resource MARK IV, developed in partnership with UNIFEI and Procel. Table 2 presents examples of software with their applications with a focus on energy efficiency.

\section{Mark IV Plus Free Software}

According to Perrone (2004), Eletrobrás has been encouraging actions of energy conservation nationwide, through the Program of Conservation of Energy-Procel, resulting in the Energy Optimization Program. One of its initial goals was to prioritize the preparation of studies for optimizing energy sectional and individual energy, from a specific software which is able to analyze the data collected on diagnostic work. In view of the improvement project and the need to have a computational tool to expedite and standardize the diagnostic performance of energy in industrial facilities, the software that became known as Mark IV was developed.

PROCEL is a tool of analysis, generation of energy diagnosis and management of the final uses of consumed energy, in which the user interacts directly with the program providing information on the analyzed installation. The software is available for download at the Procel website (MARK IV PLUS, 2009) and it can be obtained by filling out a registry so Procel can communicate with the users. The purpose of the register is to know how the program was used and what savings were generated. The user may eventually receive a questionnaire to evaluate the performance of the program. This procedure also aims to provide grants to improve the MARK IV PLUS. In a survey by the PROCEL it was obtained the number of downloads made between 2005 and 2010 as shown in Figure 1.

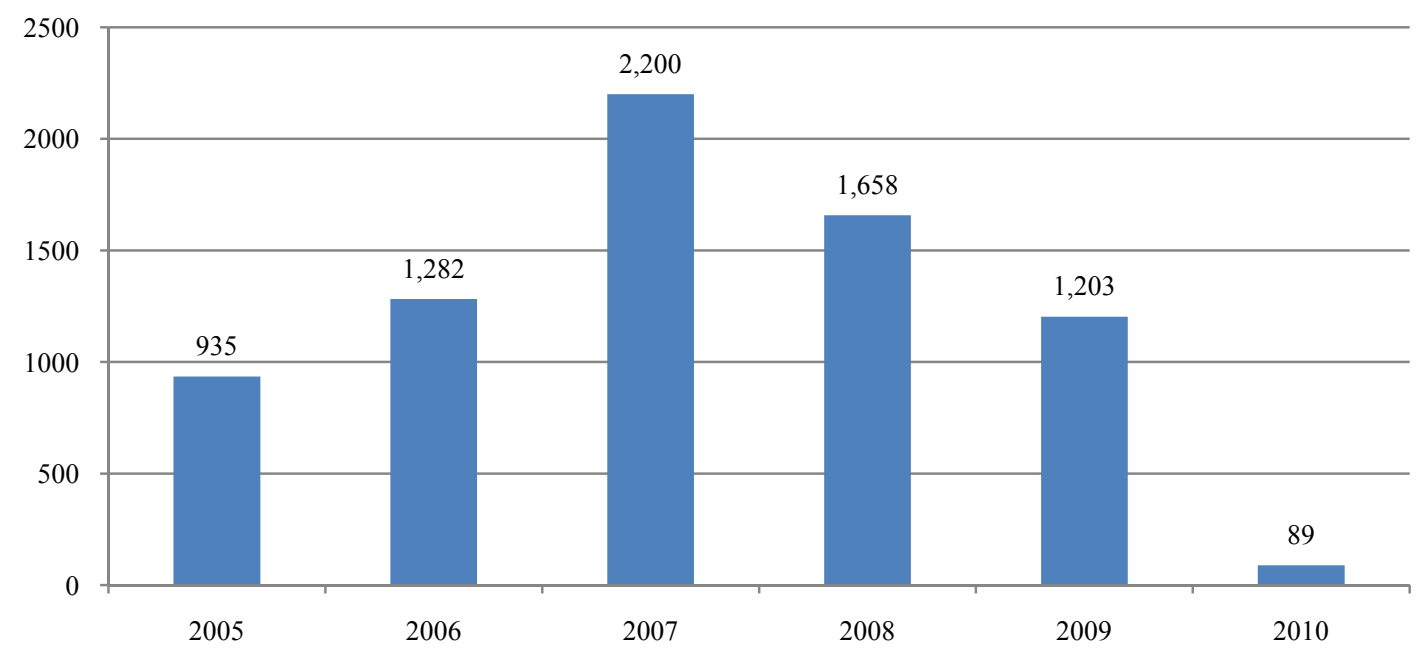

Figure 1. Evolution of MARK IV PLUS downloads. Source: PROCEL (2010). 
As Perrone (2004) mentioned, the main goals sought with the developing of this software are: to offer the user a brick and flexible tool with an easy to use analysis and energy diagnosis; cover a broad spectrum of approaches to energy analysis and optimization, as well as to expand the number of users. The application is a energy diagnostic tool in which the user downloads the program information on an electrical installation. Then, it analyzes the data, and provides as a results of the analyses, not only a report with the energy consumption, but also measures to be applied. This software features modular characteristics and consists of the following modules: main, analysis of energy bills, economic analysis, central air conditioning, window air conditioners, boilers, cogeneration, water condensers, furnaces and stoves, lighting, motors, distribution boards, cooling, processing and pipeline.

\section{Research Results: Improving Opportunities for Mark IV}

\section{Basics Assumptions}

From the literature, bibliography research and results of the questionnaires, it is intended to elicit suggestions for the improvement of the computational resource of energy performance diagnostic of the construction. The problem analysis is done in the light of three basics assumptions in the item Basics Assumptions and Research Objectives. This chapter presents the results of the survey of experts on computational resource MARK IV PLUS.

The three basics assumptions taken are: (1) the use of energy diagnosis contributes to improve energy efficiency in construction; (2) the use of diagnostic energy encourages the rational and sustainable ways of energy consumption; and (3) the use of computational resources enables the application of the energy efficiency concepts in buildings during the design stages. The concentration of specialists in Eletrobrás respondents underscores the difficulty of disseminating knowledge in the market of designers and builders. A view of the participants can be seen in Table 3.

Tabel 3

Companies Research Participants

\begin{tabular}{lcc}
\hline Company/Institution & Number of experts & Percentage (\%) \\
\hline ELETROBRÁS & 6 & 33.3 \\
EDP ESCELSA & 2 & 11.1 \\
PETROBRAS & 2 & 11.1 \\
ABNT & 1 & 5.6 \\
ANDRADES E CANELAS & 1 & 5.6 \\
CHEMTECH & 1 & 5.6 \\
IMETRO & 1 & 5.6 \\
NBS & 1 & 5.6 \\
NITTOGUEN & 1 & 5.6 \\
UFF & 1 & 5.6 \\
UNIFEI & 1 & 5.6 \\
Total & 18 & 100.0 \\
\hline
\end{tabular}


The replies to Question 5 have evidenced that the most frequent use for systems analysis of motive power were the software EXCEL and MOTOR BD, followed by the lighting. In this case Excel spreadsheets for data processing of energy efficiency are used, as well as the software: MARK IV PLUS, CALCALUX, DIALux, ULYSSE, as shown in Tables 4-5.

Table 4

\begin{tabular}{lll} 
Software Used & & \\
\hline Software used & Number of experts & Percentage $\left(^{*}\right)(\%)$ \\
\hline BD MOTOR & 3 & 16.7 \\
EXCEL & 3 & 16.7 \\
MARK IV & 2 & 11.1 \\
CALCULUX & 1 & 5.6 \\
DIALUX & 1 & 5.6 \\
ULYSSE & 1 & 5.6 \\
Não responderam & 9 & 50.0 \\
\hline
\end{tabular}

Note. (") Base rate: 18 experts.

Table 5

Final Use Evaluated With Computational Tool

\begin{tabular}{llc}
\hline Use final applied & Application & Percentage $\left(^{*}\right)(\%)$ \\
\hline Lighting & 4 & 22.2 \\
Cooling & 1 & 5.6 \\
Heating & 2 & 11.1 \\
Motor & 5 & 27.8 \\
No Information & 1 & 5.6 \\
Not answered & 9 & 50.0 \\
\hline
\end{tabular}

Note. ( ) Base rate: 18 experts.

The eight respondents who employ computational tools said that they are easy to use as you analyze the responses provided to question 6.

Analyses of the question 7 evidenced by the experts that the ways of using the concept of energy diagnosis are: (1) Make suggestions according to the energy diagnostic deployments and the changes under the user responsibility; (2) Performing technical-economic analysis of the payback time "payback"; (3) Transferring knowledge related to conservative measures; Applying measures to retrofit; Evaluating and adjusting the levels of illumination associated with the quality and efficiency of equipment, simulating different types of configuration/topology of illumination; and (4) Applying energy efficiency policy.

Based on question 8 answers, the difficulties of using computational tools indicate:

(1) Non-interchangeability between the used software; and specific software headed only for a final use of energy; and (2) Need to update the programs database, lack of dependability.

The eight respondents who employ computational tools said that they recommend its implementation, as we analyze the responses provided to question 9.

Studying the possibility of computational tools helps in the awareness of the need to employ processes which use less material and energy resources, pollute less and use cleaner technology (question 10), 38.9\% of experts surveyed agreed with this statement. 
In parallel with the interview researches were held to assess the functioning of the computational instrument MARK IV PLUS, used for simulation and energy diagnosis. It was found that this software allows the user to analyze data of energy consumption in the following final uses: lighting, electrical panels, transformers, motors, boilers, furnaces, window air conditioner, central air conditioning, refrigeration systems, condenser water and pipes.

After entering data in the current situation of the building under consideration in the computational tool MARK IV, the system provides tips on facilities improving by proposing the use of efficient equipment. In the module of the electricity bill, tariff analysis software runs simulating the cheapest financially hiring to be established between the user and dealer. In the analysis simulation of the final use of lighting, there was the need for registration of a greater number of types and models of illuminations and lamps to allow its use in buildings.

As the database is close, and it is necessary to constantly update the information, we suggest the creation of the possibility of entering data and even perform methodology of calculation of energy efficiency. In economic analysis module, we suggest the inclusion of information generated in the electric size economy, as well as providing the details of the calculation methodology used. In order to use MARK IV, it is necessary that the user is aware of the values related to the technical information of the equipment which to be replaced, otherwise the simulation cannot be done due to lack of data. Segatto-Mendes (2006) draws attention to the technological cooperation between universities and companies to develop technological solutions and management methods, as well as energy audit, aimed at achieving higher levels of energy efficiency.

\section{Conclusion and Suggestion of New Research}

The research found problems due to the lack of knowledge concerning the computational resources by the studied sample of experts concerning. There is a little emphasis on computational resource studies provided by research and educational institutions. It can be concluded that the use of computational resources for simulation and energy efficiency analysis at buildings is not usually performed by civil construction companies in Brazil. It was verified that there is a gap between theory and practice. There is a distance among the discourse of governmental research and teaching institutions, the academic production and the effectively market application of computational tools.

One of the premises that guided this work was based on the principle that the use of energy analysis can improve the energy efficiency at Brazilian civil construction. The research results confirm the importance, according to consulted experts, of the computational tools for energy analysis execution. These computational resources contribute for consciousness-raising on the need for employing processes that reduce consumption of material and energy resources and also that produce less pollution. In sum, they create a motivation for using cleaner technologies at civil construction. A secondary achieved result was to understand/contribute with suggestions of design/“retrofit" analytical systems by using computational resources. Another secondary result refers to the question: Does the energy analysis create energy consumption criteria in a very conscious way? The research has observed that the use of energy analytical tools develop more conscious consumption criteria for civil construction industry and building users. The main question of this research is to analyze if it is possible to improve the computational tool MARK IV PLUS: The guidelines for improvement were defined, based on the application of the two questionnaires, where, first of all, institutional, market and government policies are 
suggested. An important fact to improve the dissemination of the energy efficiency culture is the creation of an online course multimedia module in order to practice the use of MARK IV PLUS in order to qualify more users on management of their energy consumption. The creation of home application module with the purpose of disseminating the referred software at high schools is suggested in order to create the possibility of interferences performed by teenagers at their own house economy and also through energy saving and GHG emission reduction procedures. It also allows directing such saved energy potentiality to other parts of society, ensuring efficiency of the public policy criteria. Regarding the release of the simulator PLUS MARK IV, the suggestion is that the software can be released by electrical energy utilities so that the benefits might be used by the society as a whole. Currently, it is acknowledged that companies and governments should not only think about being in compliance with environmental laws, but they should have pro-active actions and plan their activities in a sustainable manner. They should not only account for shareholders and creditors, but also for a much greater range of interested people, creating a broad audience identified as stakeholders and society. These ones influence the governments in developing public policies that establish energy efficiency standards for the buildings in Brazil.

Secondly, the possibility of expanding the evaluation of buildings concerning the sustainability (environmental, social and economic aspects) was analyzed during the design and the execution of buildings. The importance of computational tools in achieving energy analysis was confirmed. The energy analytical systems create a market motivation towards a more rational energy consumption. There is no established competence at market or contacted universities regarding the training of technicians (architects, engineers and middle level personnel) for the use of computational resources for simulation and energy efficiency analysis at buildings during the stages of design or use. In virtue of the large investments made in Brazil in 2011 regarding the building of dwellings, the innovative aspect of production technologies at civil construction industry shall be urgently disseminated. Based on the research experts, it was found that Brazilian companies do not implement investments for developing competences and acquiring computational resources for simulation and analysis of energy efficiency. Based on the testimonials, in case there is any decision to purchase software applied to energy analysis at buildings, the preference is to acquire software systems from international market.

Besides, the survey of simulation and energy efficiency analysis practices at buildings, some guidelines for disseminating the use of simulation and energy efficiency analysis were identified during the design, use and building repair (retrofit). This research proposes a set of market endeavors to achieve this goal. It is considered that the introduction of computational resources in order to support simulation and energy analysis at buildings comes from three not-excluding conditions: (1) Own endeavor on acquiring knowledge about simulation and energy analysis by professionals involved in design, planning, execution and repair of buildings; (2) Acquisition of market software; and (3) Development and implementation supported by external consultants.

In the first alternative, the fundamental point refers to vocational training. In order to have a professional feel encouraged in enterprising such activity by his/her own initiative, along with pressure for results, it is crucial that he/she has had training in the areas of simulation, information technology, sustainability concepts, concepts of energy and energy efficiency.

Apart from technical knowledge, the professional needs to learn skills that ensure success in this initiative. 
As the practice of using computing resources of simulation is not widespread in companies, the first contact and experience must also occur during the undergraduate teaching experience or post-graduation courses. Besides the process of acquisition of theoretical knowledge, the remaining stages of a project of this nature also require some skills that can be only developed with practice. Thus, it is recommended that the undergraduate and postgraduate courses have a greater emphasis on simulation for the sustainable use of resources, especially the energy ones. And that they provide students opportunities to develop practical work as a team under actual conditions of enterprises. If this initial experience is successful and if these professionals have access to reference materials (not just textbooks) and professional support in the process of continuing education, you can gradually change the current frustrating reality.

Another way to facilitate the introduction of computational resources for simulation and diagnosis of energy is through software vendors. Currently, it is difficult to evaluate the models embedded in the software, hidden by suppliers for commercial reasons. Cooperation between academia and these companies should contribute so much to enrich the products offered on the market, as to provide opportunities for relevant research and, consequently, production of new knowledge. This cooperation also helps to open a new perspective for professional engineers and architects involved in construction, embodied in the activity of developing energy management systems. This partnership with software vendors is also considered strategic by Robinson and Dilts (1999).

Finally, the consulting activity, performed by professionals working for private companies or even in academia, is also an important channel for spreading computational resources for simulation and diagnosis of energy resources. The rapprochement between research centers and companies should contribute to the development of research and generating new knowledge on energy efficiency in buildings. The university-enterprise integration through education and research, should lead to the production of new knowledge and vocational training quality.

Due to the particularities of this research, the list that follows relates some future suggestions to expand knowledge of the use of computational tools in the field of energy efficiency management: To find the reason for the reduction of the amount of "downloads" of the software MARK IV PLUS since 2007; To evaluate the goals of the people who "download" program MARK IV PLUS; To expand the study to assess the applicability of computational tools RETScreen, Energy Plus, DOE- 2, and also, the use of energetic diagnoses in residential and commercial buildings; To check the importance of computational tools; and, to find the current barriers for the non-use of computational tools in energy audit.

\section{References}

Alves, A. L. M. (1998). Diagnosis of energy opportunity cost reduction and increased efficiency. EPUSP, São Paulo.

Barbosa, P. R. A. (2007). Corporate sustainability index of the stock exchange in Sao Paulo (BOVESPA ISE-): Review of appropriateness as a reference for improving the sustainable management of enterprises and formation of investment portfolios guided by principles of corporate sustainability (MBA Thesis, Federal University of Rio de Janeiro (UFRJ), COPPEAD Institute of Directors).

Chvatal, K. M. S. (1998). The architectural project in Campinas, SP, and guidelines for the design of buildings suitable for the climate (MA Thesis, University of Campinas).

Crawley, D. B., \& Huang, Y. J. (1997). Does it matter which weather data you use in energy simulation? User News, 1(18), 2-12. 
Crawley, D. B., et al. (2005, July). Contrasting the capabilities of building energy performance simulation programs (p. 56). U. S. Department of Energy.

Crawley, D. B., Hand, W. J., \& Lawrie L. K. (1999). Improving the weather information available to simulation programs. In International Conference IBPSA, Kyoto. Kyoto: Building Simulation.

Dunovska, T., Drkal, F., \& Hensen, J. (1999). Barriers and solutions to $h$ and use of building simulation in the Czech Republic. In International Conference IBPSA, Kyoto. Kyoto: Building Simulation.

Haddad, J., et al. (2007). Conservation of energy_Energy efficiency of equipment and facilities (3rd ed.). Eletrobrás/PROCEL Education, UNIFEM, 2006.

Haddad, J., et al. (2007). Energy efficiency-Theory and practice (1st ed.). Eletrobrás / PROCEL Education, UNIFEM,

IPCC. (2007). Chapter 14: Latin America. In J. J. McCarthy, O. F. Canziani, N. A. Leary, D. J. Dokken, \& K. S. White (Eds.). Climate change 2001: Impacts, adaptation and vulnerability. Inter-governmental Panel Climate Change IPCC. UNEP/WMO. Cambridge University Press. UK.

Junior Gitahy, A. L., \& Farias Filho, J. R., \& Alley, Osvaldo, L. G. (2006). Application of Lean Construction (Lean Construction) in the orientation of the physical arrangement of the construction site construction-buildings subsector.

Lamberts, R., Dutra, L., \& Pereira, Fernando Oscar Ruttkay. (2009). Energy efficiency in architecture. São Paulo.

Lee, W. J., \& Kenarangui, R. (2002). Energy management for motors, electrical systems and equipment. IEEE-Transactions on Industry Applications, 38(2), 602-607.

Lee, J. M., Kim, J. S., \& Kim, J. J. (2003, June). Evaluation of the 200 MWe CFB boiler performance with Tonghae cyclone modification. Energy, 28(6), 575-589.

Lee, W. L., Yik, F. W. H., \& Jones, P. (2003, June). The interactive strategy for Prioritising energy efficiency Measure for enhancing gifts of air-conditioned buildings. Energy, 28(8), 877-893.

Maliska, C. R. (2001). Issues on the integration of CFG to building simulation tools. In International IBPSA Conference (Building Simulation), 2001, Rio de Janeiro. Rio de Janeiro: IBPSA, 1, 1373-1380.

Mathews, E. H., \& Richards, P. (1990). A tool for predicting hourly air temperatures and sensible energy loads in buildings at sketch design stage. Energy and Buildings, 14, 61-80.

Mathews, E. H., Heerden, E. V., \& Arndt, D. C. (1998). The tool is integrated HVAC/building/energy and control analysis Part 01 overview of QUICK control. Department of Mechanical Engineering, University of Pretoria, South Africa.

Matthews, H. S., Lave, L., \& Maclean, H. (2002). Life cycle impact assessment: A challenge for risk analysis, 22.

Meiriño, M. J. (2004). Architectural elements should incorporate energy efficiency (p. 2). Project Design, 291.

Melo, A. P., \& Native M. (2009). Handout of the basic course of energy plus. Laboratory for Energy Efficiency in Buildings. Florianopolis, September.

Mendes, N., Westphal, F. S., Lamberts, R., \& Neto José, A. (2005). Bellini da Cunha. ARTICLE: Use of computational tools for analysis of thermal and energy performance of buildings in Brazil. Revista Built Environment, Porto Alegre, 5(4), 47-68.

Motta, A. L. T. S. (n.d.). A study of the performance of buried pipe predicted roof pond and cooling systems for low cost.

Norman, W., \& Macdonald, C. (2003, March). Getting to the bottom of "triple bottom line". Business Ethics Quarterly.

Oliveira, D. P. R. (2004). Strategic planning: concepts, methodologies and practices 21. New York: Atlas.

Perrone, F. P. D., Tabosa, R. P., Lima, M. Q., Eletrobrás, ... \& Akira, R. Y. (2004, July). UNIFEI-New software for optimizing energy and commercial facilities industrial electricity modern. Journal, ano XXXII, 364.

RETScreen. (2011). A standardized tool for assessing potential renewable energy projects, natural resources Canada, Quebec, Canada. Retrieved from http://www.retscreen.net/

Robinson, A. G., Dilts, D. M. (1999). OR \& ERP: A match for the new millennium? OR/MS Today, 26(3).

Segatto-Mendes, A., \& Mendes, P. (2006). Nathan university-industry technological cooperation for energy efficiency: A case study. Rev. adm. contemp., 10, 53-75.

Sentelhas, R. (2004). Instrument software research support possession of equipment and energy use habits of electrical (p. 130). São Paulo.

Sola, A. H., \& Kovaleski, V. J. L. (2006). Energy efficiency in industry: Scenarios and opportunities. ENEGEP XXIV National Meeting of Industrial Engineering. Florianópolis, SC. November.

United Nations Environment Programme. (UNEP). (2007). The building and construction sector: Cornerstone of sustainability. UNEP Industry and Environment. 


\section{Appendix A: Questionnaire I}

\section{Architectural/Urban Dimension}

(1) What kind of enterprise the software was applied?

( ) Residential ( ) Industrial ( ) Commercial and Service

(2) The environment where the building is installed.

( ) Rural ( ) Urban Centre ( ) Industrial

(3) The results obtained with the program helped him to recommend the use of the day lighting, natural ventilation in the reviewed building?

( ) Yes ( ) No

(4) The use of the program creates new opportunities for projects in architecture, influencing the creative process with a focus on energy efficiency?

( ) Yes ( ) No

\section{Economic Dimension}

(5) The use of the system allows the user to achieve a more efficient fuel, reducing the need for new investment in power generation?

( ) Yes ( ) No

(6) With the implementation of the measures suggested by the program was there reduction in the total energy consumption due to a more efficient use?

( ) Yes ( ) No

(7) What is the value of energy savings ( $\mathrm{kWh} /$ month) obtained with those measures?

( ) Lower/same $(15,000)$ less/equal 25,000 ( ) greater than 50,000

(8) What is the value ( $\mathrm{R} \$$ ) of the investment made?

( ) Lower/same $(15,000)$ less/equal 25,000 ( ) greater than 50,000

\section{Ecological Dimension}

(9) Was it recommended the application of any measures to reduce water consumption?

( ) Yes ( ) No

(10) Was it recommended the application of some system of energy generating from renewable sources?

( ) Windmill ( ) Solar ( ) Biomass

(11) Was it recommended the creation of green space?

( ) Yes ( ) No

(12) The application of computational tool helps to raise the awareness of the need to employ processes that use less material, energy resources that pollute less and use cleaner technologies.

( ) Agree ( ) Disagree

\section{Social Dimension}

(13) Does MARK IV contain the management measures focused on staff training in order to create an environment of awareness among employees?

( ) Yes ( ) No 
(14) Was it recommended management measures directed to the staff training, aiming to create awareness among employees?

( ) Yes ( ) No

(15) Is it possible to observe recommendations, in MARK IV's final report, to help to improve the awareness of the need to implement energy efficiency measures?

( ) Yes ( ) No

(16) The use of MARK IV can help people without expertise in the application of energy efficiency measures.

( ) Agree ( ) Disagree

\section{Political Dimension}

(17) It is considered to be positive the PROCEL participation in spreading the culture of energy efficiency.

( ) Agree ( ) Disagree

(18) What is the percentage of the buildings considered part of environmental or social projects in partnership with Government Agencies?

( ) Equal to $0 \%(\quad)$ or less $(25 \%) \leq 50 \% \quad$ ( ) Or less $(75 \%)$ equal to $100 \%$

(19) It is conducive to establishing a network of intelligent power distribution, where there was the possibility of hiring an energy tariff custom and turn off selected appliances during peak hours to reduce the demand of the electric system.

( ) Agree ( ) Disagree

(20) What kind of guidelines for energy efficiency program do you suggest for Public Policy?

( ) Encouraging the use of solar water heating ( ) Incentive coogeração and distributed generation ( ) Implementation of energy efficiency programs in higher education institutions ( ) Other (Specify)

\section{Appendix B: Questionnaire II}

(1) Do you work with energy efficiency?

( ) Yes ( ) No

(2) Do you use a computational tool to implement energy efficiency measures?

( ) Yes ( ) No

(3) Do you use the MARK IV?

( ) Yes ( ) No

(4) What software do you use the most?

(5) To what final use do you apply?

( ) Lighting ( ) Cooling ( ) heating ( ) motor

(6) Do you consider the software you use, easy to use?

(7) How do you implement energy efficiency measures? 
(8) What are the biggest difficulties that you can identify in using the simulation tool?

(9) Would you recommend the use of computational simulation tool energy? Comment it.

(10) The application of computational tool helps the raise of the awareness of the need to employ processes that use less material and energy resources that pollute less and use cleaner technologies.

( ) Agree ( ) Disagree 